\title{
The Roles of Communicative Language Mechanisms in Occupational Health and Safety Milieu in Reducing Workplace Hazards
}

\author{
Ravnil Narayan \\ Department of Communications and Media, School of Communications, Languages and Literature, College of \\ Humanities and Education, Fiji National University, Fiji Islands \\ Vikrant Krishan Nair \\ Department of Occupational Health and Safety, School of Applied Sciences, College of Engineering, Science and \\ Technology, Fiji National University, Fiji Islands
}

\begin{abstract}
Workplace safety communication plays an integral role in the day to day running of any organisation. The policies and procedures tend to provide a worker with the highest level of performance that is expected in terms of the output. Effective communication mechanisms are highly critical to ascertain the level of safety measures in order to achieve support and cooperation in maintaining an injury-free working milieu. Hence, communicative language mechanisms are needed to complement the technical and practical safety of all the workers. Unambiguous constructive safety communication mechanisms will lead to an improvement towards knowledge and fathoming of preventative measures that would enhance workplace safety practices. Thus, this study sought to highlight the occupational health and safety communicative language mechanisms, whereby the examples to illustrate the variety of safety communication has been analysed from a case study. The output of the research states that communicative language mechanisms in occupational health and safety (OHS), health and safety environment (HSE) tend to provide a better working environment, which can be considered as a conducive tool to avoid unwanted injuries and also to comprehend complicated occupational health and safety technical jargons.
\end{abstract}

Index Terms - language mechanisms, occupational health and safety (OHS), health and safety environment (HSE), communication strategies, communication barriers, hazards

\section{INTRODUCTION}

Communication tends to allow people to interact with each other purposively and cooperate as one so that a consensus is reached to avoid any sort of unwanted workplace injuries. The paramount reason for health, safety and environment's (HSE) objectives are to make the workers aware of the hazardous encounters that may arise from a misconception of occupational health and safety protocols. While communicating about the facets of safety communication whether it will have any influence on the workers or not, the language mechanism will determine the acceptance or rejection of the protocols. However, those who are infants and working as trainees may be having a lot of problems in comprehending the safety measures of an organisation. Hence, an atmosphere of safe behaviours through simple communicative instructions will oversee that fewer workers are involved in unprecedented injuries and a conducive working environment is created.

In the day to day interactions between the workers of an organisation, the occupational health and safety sentient people play an integral role in overseeing the probable hazards. According to Lavy et al., (2010), language difficulties mainly create a barrier towards effective communication, which in most instances leads to misunderstanding, confusion and other ineffective communication-related issues. This is mainly experienced through mediated communications via emails, text messages, telephones, written instructions and so forth. The technical and non-technical aspects of problems and issues experienced by workers, including the OHS/HSE personnel foreshadows a challenging task of dealing with workplace safety cultures. It is believed that the process of safety communication involves sound language mechanisms, as it involves higher management authorities and individuals at a lower level of the workplace. This becomes more challenging when multiple groups of people are involved.

Many organisations employ workers to meet the production demands, however, they fail to realise the imperativeness of their part in informing the occupational health and safety guidelines to them. In many of the instances, communication barriers cause such problems of not imparting the occupational health and safety guidelines due to the level of education of the workers. As asserted by Booth (1993), the minimisation of workplace injuries can be achieved through having the right attitudes, competencies and patterned behaviour of the organisation and workers. Subsequently, this will also assist the organisation in committing towards workplace health and safety, which will create an ambiance of injury-free production for the organisation. Hence, this paper will delve into the communicative mechanisms of 
occupational health and safety language and how it could contribute towards a reduction in hazards.

\section{LITERATUR REVIEW}

In any given organisation the optimistic culture of the communicative mechanism is sufficed by the founding of mutual trust and shared ideologies between the workers and organisation. It is further supplemented by efficacy and confidence towards all the preventative measures that could trigger any sort of workplace accidents. Engaging in effective communication and providing consultations at work is highly crucial towards achieving a safer working environment. This is imperative to reduce the hazards and control risks so that the attitudes and behaviour of the workers could be reconsidered for a safer working environment. According to table 1 given on the next page, the communication elements sought to provide strategies in achieving optimistic safety culture (Geller, 1998; Reason, 2002; Comcare, 2004; Hopkins, 2005).

An organisation that practices two-way communication should be providing its workers with pertinent information regarding risks and hazards, which should be in association with the organisation's structural operation concerning workplace safety matters. More so, the organisation should also be giving attention to the grievances of its workers and provide authentic solutions to them. According to Wilkins (2011), it is strongly believed that workers are going to contribute towards greater productivity if there is going to be a proper framework for communications. The framework should be embedded with simple communicative measures that would allow the workers to comprehend the language of occupational health and safety, which could prepare them for possible hazards and near-miss mishaps. Engaging workers in an organisation's decision-making processes regarding occupational health and safety culture would create mutual understanding.

To add on, communicative language mechanism is defined as the approach of using language that dwells upon the communicative competence of its users (Cannale, 1983; Cook, 2013; Littlewood and William, 1981 and Rivers, 1986). According to Richards and Rodgers (2001), the communicative learning mechanism emphasises the goal of language learning communicative competence. On the other hand, Littlewood (1981) explains that, "one of the most characteristics features of communicative language learning is that it pays systematic attention to functional as well as structural aspects of language, combining these into a more fully communicative view". In the occupational health and safety context, the language of instruction plays an integral role in conceptualising the contents of hazards and other related aspects of it. The communicative approach uniquely defines the individual needs of the workers.

Additionally, consultation and communication at the workplace are crucial towards achieving a safe working ambiance, which is only possible through giving and receiving information that includes risk controls and hazards that influences behaviour and attitudes in building ownership and commitment (Geller, 2001). In terms of two-way communication, the management tends to provide workers with pertinent information on risks and hazards that are associated with the company's operations in building an understanding regarding how safety at the workplace should be practiced through effective communication. The organisations are expected to listen to the worker's concern and act on it using the most effective way of communication (Sherry and Nancy, 2003). Workers are going to contribute effectively in a working environment that is going to provide a framework for correct means of consultation and communication.

Moreover, involving the workers during employer and employee discussions in regards to incidents of hazards and near misses would allow them to accomplish mutual goals. As claimed by Standards Australia (2001), this will lead to worker involvement in decision-making processes and responding to the concerns and demands of the organisation. This would further lead to sustainability and will minimise workplace hazards that will increase production without any workplace injuries. To date, scant literature has revealed not much investigation into communicative language mechanisms and its repercussions on workplace hazards and injuries (Kim et al., 2008; Lijie et al., 2012; and Kaskutas et al., 2013). It is further asserted that workplace safety communication is not about the processes of negotiating safety information, in fact, it is about influencing the behaviour of employees by changing their attitudes towards hazards.

As asserted by Alica (2009), an accident is defined as an unforeseen incident that is caused by an unconscious state. Organisations that are involved in highly hazardous activities such as in construction, aviation, medical, production plants to name a few are always leading compared to all other industries (Qureshi, 2007). However, it has been argued that it is almost impossible to avoid accidents from happening in high-risk industries (Lyneis and Madnick, 2008). The literature has revealed that every year around 2 million workers lose their lives in high-risk enduring jobs and around 270 million get involved in occupational accidents, while 160 million occupational diseases happen worldwide yearly (Hamid et al., 2008). As acclaimed by (Rahim et al., 2014), workplace accidents persistently tend to be quandary and is seen as a huge challenge for organisations to manage it. As such, to avoid accidents from happening at the workplace, managerial personnel are devoting an extra bit of effort to effectively improve workplace accidents each day every day (Wu et al., 2007).

According to Geller (2005), an organisation's safety culture is determined by the frequent communication that takes place between the employer and workers. Effective safety communication is guaranteed to provide affection on worker's behavior that would allow them to create an injury-free workplace, for example, practicing safety performance while operating heavy machines (Michael et al., 2006). However, when it comes to miscommunication, it usually takes place amongst the workers, particularly between upper-class management and employees. This arises due to the 
negligence of constructive safety communication during working hours, which could be implying the absence of good safety culture not being practiced in the organisation (Conchie et al., 2013). Hence, the table below depicts the safety culture communication mechanism that is required to reduce workplace injuries:

TABLE 1

SAFETy Culture COMMUNiCATION MECHANISMS

\begin{tabular}{|l|l|l|}
\hline \multicolumn{1}{|c}{ Safety Culture Mechanisms } & \multicolumn{1}{c|}{ Requirements } & \multicolumn{1}{c|}{ Communication Elements } \\
\hline Assigning methods to control hazards. & $\begin{array}{l}\text { - Everyone in the organisation is expected to } \\
\text { show support. }\end{array}$ & $\begin{array}{l}\text { - Demonstrating procedures and rules as a } \\
\text { reminder towards workplace safety. }\end{array}$ \\
\hline $\begin{array}{l}\text { Managing commitment towards minimising } \\
\text { risks and hazards during operations and } \\
\text { practicing compliance of safety and legislation. }\end{array}$ & $\begin{array}{l}\text { - Accepting responsibilities for HSE; } \\
\text { - Providing the right resources and accepting } \\
\text { responsibilities for HSE; } \\
\text { - Changing attitudes towards risks. }\end{array}$ & $\begin{array}{l}\text { Displaying employer's commitment, } \\
\text { expectations and values; } \\
\text { - Monitoring and supervising the works that } \\
\text { are performed. }\end{array}$ \\
\hline $\begin{array}{l}\text { Workers tend to contribute more effectively to } \\
\text { an organisation that is practicing the culture of } \\
\text { the corporation. }\end{array}$ & $\begin{array}{l}\text { - The ambiance of trust and encouragement } \\
\text { that can be rewarded in terms of HSE. }\end{array}$ & $\begin{array}{l}\text { Assessing competency level and providing } \\
\text { feedback based on HSE; } \\
\text { - Motivating, recognising and rewarding } \\
\text { workers. }\end{array}$ \\
\hline $\begin{array}{l}\text { Workers must be given the required } \\
\text { information including training to broaden } \\
\text { existing knowledge of workers and gaining new } \\
\text { skills for HSE. }\end{array}$ & $\begin{array}{l}\text { - Willingness to implement changes and } \\
\text { reforms to suit the competence level. }\end{array}$ & $\begin{array}{l}\text { Providing finer instructions on how to use } \\
\text { safety equipment and materials at all levels of } \\
\text { work. }\end{array}$ \\
\hline $\begin{array}{l}\text { Workers are most likely to contribute to an } \\
\text { environment that promotes intercommunication } \\
\text { and consultations. }\end{array}$ & $\begin{array}{l}\text { - Workers are encouraged to equip themselves } \\
\text { with PPE and report any errors or near misses } \\
\text { at the workplace. }\end{array}$ & $\begin{array}{l}\text { - Conducting meetings to address issues } \\
\text { concerning hazards and risks during } \\
\text { operational procedures of HSE. }\end{array}$ \\
\hline
\end{tabular}

(Source: Standards Australia, 2001)

So much so, the safety culture related to communication mechanisms has become an imperative domain in safety management, particularly in high-risk areas such as maritime, aviation, medical field and others (Reiman and Rollenhagen, 2014). Presently, safety culture at the workplace is influenced by the lack of communication mechanisms, which contributes to some major hazardous activities. Therefore, managerial level post holders are expected to cultivate an optimistic safety cultural atmosphere to eradicate workplace injuries (Mullen et al., 2011).

As stated by Vecchino-Sadus and Griffiths (2004), there are a few examples of safety communication. In most instances, the common ways for internal communication include the presentation of information to senior management personnel of OHS/HSE through noticeboards, memorandums, team meetings, emails, reports and other mediated communications. It is highly crucial for the information that is to be presented must be simple and straightforward so that the end-users can fathom it properly and fully (Preece and Stockings, 1999). So much so, communication types in occupational health and safety including communication sources need to be precisely justified. This would assist the workers to comprehend the instructions well and avoid any hazardous injuries or near-miss tragedies. Below is the list of mediums, which concerns communication mechanisms in occupational health and safety context.

\section{COMmunicAtion Mediums in OCCUPATIONAL HeALth AND SAFETy}

\section{A. Policies, Strategic Plans and OHS Mission Statements}

The occupational health and safety policies and mission statements are going to help define the safety procedures while justifying the instructions of workplace hazards in any given circumstances. These documents can spell out the priorities and objectives that could be used as a guiding tool in minimising injuries and accidents. All these documents should be given to workers on the first day of work so that thorough knowledge is given to all regarding OHS/HSE. In general, these documents are to be considered as a paramount document that should not be treated as subservient pages complied as a typical user manual.

\section{B. Checklists, Manuals and Operating Procedures}

Organisations' safety guiding documents such as checklists, manuals and other operating procedures are seen as consolidated rules and requirements that would assist the workers in minimising injuries and hazards. Checklist tools could be used for inspecting machines and other operating devices that would assist the workers in preventing workplace accidents. If not checked well, it could lead to miscommunication and an increase in reported hazards. Placing of maintenance logbook beside the machines would provide regular reminders regarding servicing of the machines. The operational procedures would give kind advice on safe work practices. In brief, the lock-out of fault equipment and work in progress can communicate a greater deal of workplace injuries that can cause workers to put their lives at stake. Therefore, it is highly pivotal to take all the precautionary measures in ensuring that all the machines are in workable condition and it does not pose any risk to workers. More so, the workers should equally adhere to all the operating procedures so that the checklists, manuals and other operating procedures do not go futile.

\section{Safety Inductions}

Conducting safety inductions for all recruits through OHS/HSE supervisors on emergency procedures and other pertinent information would lead to a greater awareness of potential hazards that could be encountered if a worker is 
oblivious of workplace safety issues. This will surely make the workers realise the detrimental effects of not following the OHS/HSE compliance and neglecting what is being given to them in black and white.

\section{OHS/HSE Statistics}

Organisations can communicate better with their workers through the performance of medical treatments, lost times, severity and incident rates, compensation rates and key performing indicators. These could be considered to be used to facilitate constant and consistent accountability in enhancing the line manager's role to achieve the organisation's OHS/HSE objectives, hence the workers would be well informed with the statistics and they can reflect on it.

\section{E. Risk Assessments}

Any worker who is working for an organisation is highly susceptible to risk factors without even realising it. Hazards such as chemical spillage, extreme temperatures and moving parts tend to communicate immediate threats to injuries. However, in many instances, the injuries that exist within a workplace cannot be perceived always, for example, gases that are highly toxic and has no odour. A risk assessment could assist in identifying potential hazards on people and the environment by assessing the magnitude of the potential hazards and controlling it through proper mitigations.

\section{F. Pieces of Training}

Training is considered to be a proactive approach in responding to loopholes, which requires to target highly vulnerable workers through a reactive approach and adjust the mindset of risks (Lages et al., 2008). This training will not only assist the workers in the workplace but at the same time away from the workplace as well. This includes workplace stress, personal fitness, proper hygiene and many others. To inculcate optimistic behaviour and attitude towards OHS/HSE, programs should be designed proactively with staff needs in mind. Workplace safety methods should engage workers in raising worker awareness to make them realise their true expectations towards OHS/HSE.

\section{G. Near Misses, Hazards and Accidents}

Communicating the results of hazards and accident investigation tends to demonstrate the commitment of the management in addressing and identifying underlying causes to prevent any future incidents from taking place. The involvement of workers in suggesting ways and strategies in reducing workplace injuries would encourage them to take ownership of minimising the injuries and suggest some highly effective strategies. As such, it is highly crucial to create awareness for an injury-free workplace so that the environment becomes conducive to work and production is achieved.

\section{H. Safety Week Awareness}

Workplace safety awareness week will promote a healthier and happier working ambiance by creating awareness within the workers regarding workplace communications about OHS. This kind of awareness could be considered as an excellent platform to showcase health and safety to its optimum. Activities such as video presentations, seminars, evacuation drills, medical health checkups, trade shows and promotional competitions would surely keep the workers on their toes to avoid any or all sorts of workplace injuries.

\section{THE COMMUNICATION STRATEGIES}

\section{Barriers to Effective Communication}

In any walk of life, communication plays an integral role which is undoubtedly essential to be developed in all areas. No matter how good the communication system is or how well it is formed, barriers to effective communication will always be a major concern to address (Kapur, 2018). Hence, communication in occupational health and safety involves informing, advising, train, warn, direct, criticise, seek help, motivate, reassure, question, acknowledge and complain. Typically, communication that involves benefit or threat is generally absorbed better by the end-users. As stated by Cole (2000), barriers to effective communication could be due to many reasons, such as, not giving full attention to details, lack of knowledge on particular information, not elucidating goals and priorities precisely, selective listening, self-image, lack of empathy, prejudices, stereotypes, varied perception about risks, inability to explore alternative solutions, preconceived ideologies and weak judgments. Also, barriers could occur through mediated communication. For instance, extensive use of emails could desensitise many workers to safety messages, which will have a greater impact on the overall state of the workers.

\section{TYPES OF BARRIERS IN OCCUPATIONAL HEALTH AND SAFETY COMMUNICATION}

\section{A. Environmental and Physical Barriers}

In totality, there are four types of barriers that can be categorised under environmental and physical communication barriers. Firstly, the time which one would require to respond to hazards and injuries that could occur at the workplace. Secondly, the unwanted space which creates the rift between the workers and management needs to be eliminated, as it may lead to communication breakdown. The environment in which communication takes place between the workers and organisation need not have to be overcrowded. Only those who are supposed to be addressed should be called so that the message is imparted effectively and specifically to them. Finally, the medium that is going to be used to deliver 
the intended information or message should be effective and appropriate. Whether it be through video, written, oral, informal, or formal, the medium that will be used for communication purposes should be precise, accurate and fathomable. In this manner, the target message that needs to be imparted to the workers will be delivered to them effectively and cautiously to minimise any workplace injuries or near misses.

\section{B. Psychological/Emotional Barriers}

In the process of communication, it is highly pivotal to understand all the worker's emotional sentiments and mental capacity, as this would define their abilities and disabilities in performing a particular task. If a worker is communicating with another or a group of workers with an attitude of disinterest or in an ignorant manner, then the process of communication is surely going to be ineffective and meaningless. In this sense, it could be perceived that the attitude and manner of the workers engaged in communication are inappropriate for making the communication effectual. Subsequently, the communication largely depends on the worker's mental condition, therefore, if a worker is not mentally or emotionally sound, then he/she cannot be communicating effectively either a receiver or sender of the message. Further breaking down the psychological barrier, there are six different types of it:

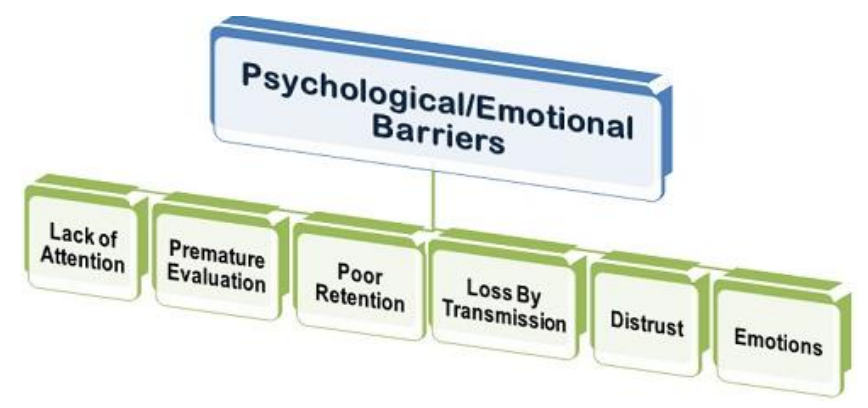

\section{Semantic Barrier}

While communicating with other workers, no matter what kind of medium is utilised, whether informal or formal, it is imperative to use appropriate vocabulary, language and all other kinds of communication skills that should reflect the decency of the communicators. The language and vocabulary that is ought to be used for communication purposes should be fathomable to the communicators. For example, at a typical construction company, a worker only speaks his/her first language and a word is used in a second language, then he/she may or may not fathom that word. Where there is an engagement in communication by two or more groups of people, one common language should be used so that all can understand, as this could avoid misunderstanding during working hours at work. This will minimise the misunderstanding between workers, as they all will be using one common medium of instruction.

\section{Perception of Reality}

During engaged communication, it is crucial to fathom a repertoire of perceptions of situations or of issues and problems. At any given workplace milieu, there will be a varied level of perceptions that involves communication about a particular topic, issue, situation, dilemma, condition, concept or stress. Considering all these and more, lacking a thorough understanding of varied levels of perceptions could be proven to be a barrier. As such, to implement effective ways of communication, it is, therefore, crucial to gain the sense of perception of reality, which simply looks into the information about knowledge, ideologies, figures, facts and actuality. During an engaged communication, there should be openness, flexibility and transparency.

\section{E. Cultural Barriers}

At any workplace, communication does not take place between two or more similar races, religions and nationalities it takes place between people from different ethnic groups, cultures, religions and races, etc. In other words, when two workers will be communicating at a workplace, there will surely be cultural differences, therefore, it is paramount to overcome this cultural barrier that might ignite misconceptions at the workplace. More imperatively, it is equally pivotal to raise awareness about cultural integrity at workplaces and how it would benefit those, whom one is communicating to. At workplaces, workers need to appreciate each other's culture so that it could not be seen as a detrimental factor in working with people from different cultural backgrounds.

Moreover, the imperativeness of communication mechanism in occupational health and safety could only be valued if the workers tend to perceive an open safety communication at their workplace (Neal et al., 2000). Lack of safety communication mechanisms would lead to inadvertent near misses and hazards in the organisation. According to Chen and Chen (2013), an upward safety communication mechanism is highly crucial to avoid adverse safety events being experienced in an organisation. The result of this would be that effective safety communication mechanisms between the organisation and workers would become an issue of importance, thus workplace injuries and near misses would be minimised (Clarke, 2006). Factually, frequently discussing workplace hazards to minimise injuries and near misses can be noted as an acknowledgment to workers in highlighting visible commitment towards OHS/HSE requirements. 
Generally, safety communication mechanisms have not only shown a reduction in the possibility of workers to take apt actions during critical moments but it has also caused safety performance in the organisation to further deteriorate (Michael et al., 2006; Kines et al., 2010; Maxfield et al., 2011). As stated by Maxfield (2001), having a communication breakdown in an organisation could be taken as an honest mistake and not to be discussed. For example, illegible handwriting, label and hazard notices that are confusing, difficult accents of line supervisors and managers (particularly expatriates) and other language barriers. All these tend to result in continued unsafe work acts at the workplace (Alsamadani et al., 2012). Although research has shown that lack of communication mechanisms is directly related to the safety of worker's health at the workplace (Lesch, 2005; Buckly, 2010; Donahue et al., 2012), there is still a lot of attention required to be given to worker's through effective communication mechanisms (Laughry, 2006; Kines et al., 2010).

More so, the safety culture communication mechanisms have presently become the crucial domain in any workplace safety management system. This could be seen in the construction industry, aviation, maritime, medical sector and road transport to name a few (Reiman and Rollenhagen, 2014). Presently, safety culture at the workplace had been recognised as one of the foremost contributing factors to near misses, accidents and injuries (Amirah et al., 2013). Therefore, it is the sole responsibility of the organisation to foster positive workplace safety culture through a good communicative mechanism system so that there are minimal workplace injuries and other related mishaps. According to Wu et al., (2010), the common sets of OHS/HSE aims, objectives and values would define and guide workplace injuries and near misses by minimising it.

\section{LANGUAGE AND VocABULARY OF OCCUPATIONAL HEALTH \& SAFETY}

What matters the most when it comes to language and vocabulary of occupational and safety is how the intended communication or message is supposed to be conveyed to the workers. The choosing of language and vocabulary could have an insightful influence on the overall outcome of safety communication mechanisms (Cole, 2000). How the organisation is going to communicate with their workers would be determined by the word choices and vocabulary. Though it could be agreed that in blue-collar professions many line managers, supervisor's and sometimes workers tend to use "decent language", despite this, communication should always be effective and authentic. Workers should be given all the privilege to express themselves openly so that no one is unheard or unseen from organisations perception.

TABLE 2

EXAMPLES Of OCCUPATIONAL HEALTH AND SAFETY MeChanisMS

\begin{tabular}{|l|l|}
\hline \multicolumn{2}{|c|}{ Pessimistic Phrase } \\
\hline You are always having problems. & We need better solutions for you. \\
\hline You have to fulfill the requirements. & Work will be designed according to their needs. \\
\hline You are creating a nuisance. & Reduce your noise level, please. \\
\hline Management Representatives have demanded... & Management Representatives have made a decision. \\
\hline Ensure workers are there during the meeting... & Ensure workers feel included during the meeting. \\
\hline $\begin{array}{l}\text { Worker can't understand the OHS procedures written on the wall } \\
\text { because he is uneducated. }\end{array}$ & $\begin{array}{l}\text { Worker understands vernacular language only, therefore safety } \\
\text { procedures should be explained to him accordingly. }\end{array}$ \\
\hline Workplace accidents are less now. & Workplace safety has improved. \\
\hline Too much information is being communicated all at once. & We have to work on communication barriers. \\
\hline Your safety instructions are confusing. & Can you please rephrase your instructions? \\
\hline You are such a mess. & You require better housing keeping methods. \\
\hline I want an earmuff. & I'd like to have an earmuff. \\
\hline Send me the OHS audit report. & Could you send me the OHS report? \\
\hline You are wrong about the procedure for the fire drill. & You might be mistaken about the fire drill procedure. \\
\hline You are bad at handling safety equipment. & You need to use your safety equipment carefully. \\
\hline You are critising all the time. & You can express your views freely. \\
\hline
\end{tabular}

Based on the examples given above, it could be stated that based on the commands from the top-level management, feedback to the responses from the workers is highly crucial as an optimistic and pessimistic response could have an influential behaviour at the workplace. Effective and straightforward feedback needs to be provided to the workers with objective words (Rivers, 2007). Using subjective language and ambiguous words could be counterproductive, which can live the workers in utter limbo and frustration. For instance, statements like this, "It implies to me that you are careless, unaware and lazy". A Statement like this only adds resentment and low self-esteem to the behavioral message, which demoralises the workers in long run (Geller, 1996).

\section{A. Criticisms and Complains}

In any organisation, the OHS/HSE officers can face a great deal of resistance in enforcing and changing existing workplace rules and regulations. What matters the most is the outcome and reaction of the workers concerning the implementation of those rules and regulations. The examples given below demonstrate the lack of cooperation and frustration elicited by workers: 
TABLE 3

EXAMPLES OF CRITICISMS AND COMPLAINS OF OHS COMMUNICATION MECHANISMS

\begin{tabular}{|l|}
\hline Changing safety procedures will be difficult... \\
\hline I am not comfortable wearing PPEs... \\
\hline I am just an OHS rep, who will listen to me... \\
\hline Your safety is not my concern... \\
\hline Having OHS related placards will be costly... \\
\hline Since there's no legal liability, I can miss the OHS committee meeting... \\
\hline It is not possible to go for training at my age... \\
\hline We can compromise a bit on worker's safety since our investment is big... \\
\hline
\end{tabular}

An organisation is a place where many people are more sensitive than others. As such, many do not like the negative criticisms being provided to them. When highlighting errors for unsafe work practices and other work-related matters, workers are indefinitely going to come up with excuses to defend themselves when interrogated. However, as stated by Geller (1998), communicating to the workers by showing some valid points for errors and suggesting solutions to prevent it in the future will surely have a long-lasting impact on taking all the criticisms healthily. Translating all the negative feedbacks and criticisms into specific requests will create a lesser misunderstanding between the workers and the organisation.

To gain effective cooperation from the workers, it is highly crucial to use communication that involves specification and optimistic language rather than generalisations. For example, "why", "somebody should", "it would assist me to", "if you could/would". Also, using non-inflammatory and non-judgmental phrases like, "I perceive...", "it implies to me...", etc. According to Rivers (2007), a reiteration of subject matters that communicates nothing but personal attacks between workers and supervisors will most likely create a rift between the two. Identification and rectification on common grounds of mutual understanding will solve the problem of miscommunication.

Subsequently, due to misunderstanding and riff being aroused between the workers and organisation, this leaves the workers to be more vulnerable to being rebellious, which would later lead to serious repercussions being conspired from their end towards the organisation. In many instances, workers start to be ignorant of their line managers and supervisors, thus favorable working milieu is rarely created at the workplace. Therefore, it is highly pivotal for the organisation to hear out to its workers and work out reasonable solutions to their problems.

\section{B. Questions and Interrogations}

In occupational health and safety, closed question tags (such as yes or no) tend to have an impediment on doubts, while probing questions would provide more justified and open responses from the workers pertaining to specified subject matters. In other words, we tend to ask questions of 'how' which addresses the prospective future actions and 'why' for retrospective actions. In the field of occupational health and safety, the 'how' interrogative word becomes useful in seeking elucidations of a particular work procedure, which is less confronting in asking 'why' questions. In an incidental investigation, 'why' questions assist in identifying causes rather than engaging workers in blaming each other. The workers also need to be mindful that their attitude towards the workplace would determine their long-term career prospects with the organisation. The better the attitude of the workers, the more chances for professional growth would be experienced by the workers.

Nonetheless, in many other circumstances, a repeated asking of 'why' tends to identify many other related chains of causes that would vary from one situation to another, which may contribute towards unsafe behaviour exposited from the workers (Geller, 2002). The table below shows the 'why' usage more than two times, which precisely indicates the fundamental issues for further interrogation of a particular problem. More imperatively, in many of the instances highly effective communication is vital towards the development of optimistic safety culture at the workplace. Developing and implementing communication mechanisms and informing the respective stakeholders regarding what needs to be known about workplace safety communications would create a clearer understanding between the organisation and workers (www.croneri.co.uk, 2020). There is a high probability that workers would be enjoying their work and minimal or no injuries would be recorded on a particular day. In this sense, the OHS/HSE rules and regulations could be considered as the apt communicative language mechanism for the workers to exhibit their admirable ability in working for an organisation, where zero accidents are being experienced by them.

TABLE 4

EXAMPLES OF QUESTIONS AND INTERROGATIONS

Step 1. While working

Q: Why are you not wearing any safety shoes?

A: It doesn't fit well. It's loose.

Q: Why don't you get it changed in the storeroom?

A: All the safety shoes there are of the same size.

Step 2. Enquiring at the storeroom

Q: Why all the safety shoes are of the same size?

A: Because it's cheaper for the company to buy one size in lots.

Step 3. At the OHS meeting

Q: Why hasn't anyone raised the issue of same sized safety shoes?

A: Because no one from the management takes action on our suggestions. 


\section{CASE Study on Communicative Language Mechanisms at Dominion WiRE ANd CABLES, BA}

Dominion Wire and Cables PTE Limited is the manufacturer and provider of cables solutions for vitality, correspondences, information and mechanical segments in Fiji and the South Pacific including Australia and New Zealand. The organisation offers undeniably something beyond link generation by uniting related items and testing administrations; Dominion Wire and Cables PTE Limited can give a total link bundle. The organisation was set up in 1980 and is a noteworthy supporter of Fijis foundation and monetary improvement. It pursues ISO 9001:2015 Quality Management System with TUV Rheinland Australia affirmations with best practices, shared learning and the best specialised assets accessible is a distinct to adjustment to different world-class norms.

At Dominion Wire and Cables PTE Limited, no structure is too large or small. The organization is developing firmly, especially in Fiji and the Pacific Island markets with new creation lines and a huge increment in staff alongside the development of another distribution center to cater for the expanding demand. Dominion Wire and Cables PTE Limited has a distribution network all through the Pacific Islands and a group of individuals resolved to meet the all-out requirements of their clients - from client details to giving upgraded coordination and an exceptional dimension of specialised help. The organisation becomes consistently dependent on sound business rationality of giving quality items utilising driving edge innovation, upheld by unfailing brilliance in client administration and quicker turnaround time to keep up client faithfulness. These are convictions and qualities that give them the quality and certainty to keep on developing, exceed expectations and succeed.

More imperatively, the management is firmly committed to a policy enabling all work activities to be carried out safely and with all possible measures taken to remove (or at least reduce) risks to the health, safety and welfare of employees, contractors, authorized visitors and anyone else who may be affected by their operations. "We are committed to ensuring we comply with the Health and Safety at Work Act 1996, along with relevant Regulations and applicable codes of practice". Environmental sustainability is something that has now become of great importance due to the looming threat of climate change. Dominion Cables acknowledges this and has put in place policies to assure that our manufacturing processes do not violate or degrade the environment in any way, as the workers are equally concerned here. Enumerated below is the communication mechanisms for health and safety environment, which is disseminated by the organisation to their workers:

- Firstly, the higher management system of the organisation looks into occupational health and safety issues and concerns;

- Documents such as Health and Safety Work Act 1996, Health and Safety Work Act (Representatives and Committees) Regulations 2007, Health and Safety Work Act (General Workplace Conditions) Regulations 2003, Occupational Health and Safety policies, procedures, accident/incident register, training needs analysis, action plans, emergency evacuation plan, fire drill documentation and occupational health and safety meeting minutes;

- Any new policies, plans and procedures that are implemented are released to the workers with a communication plan that spells out the requirements of the organisation;

- All the line managers and supervisors including any other workers, who are leading the occupational health and safety department are obliged to attend compulsory OHS training that is organised by the company or external organisations. This would assist them to better equip themselves in terms of their roles and responsibilities concerning health and safety environment. The training would mainly comprise of risk assessments, HSE procedures and incident reporting;

- An organisation that has an active webpage and has policy forms, such as, risk assessment, incident report, policy information and general awareness topics on it would assist the workers in having proper and immediate access to online OHS needs and requirements;

- Occupational Health and Safety performance measurements;

- Frequent inspection of the workstations/workshops and reminding the workers about workplace safety communication would see a reduction in near misses and other injuries.

Dominion Wire and Cables PTE Limited seeks the cooperation and mutual understanding of not their workers only but the visitors as well in terms of minimising workplace injuries through effective communication mechanisms. The health and safety environment requires all the workers to adhere to occupational health and safety protocols and abide by it strongly. Decisions on communication mechanisms that include "what, when, where, whom and how" is considered to be the overall safety strategical means in interrogating workplace injuries and near misses. The organisation also practices stringent adherence to all occupational health and safety policies.

In addition, the organisation also initiated a workplace safety communication operation that was particularly designed to implement an injury-free working environment. The organisation campaigned about intervention strategies that comprised of communication mechanisms in improving injury statistics that contributed towards near misses and severe bodily injuries. The staff appeared to value the reporting of all the workplace injuries and any other serious mishaps at the workplace. The organisation also highlighted the importance of communicating with each other during the workplace should they encounter any severities while working. In addition, a few questions were also disseminated to the workers to provide their feedback in regards to how communication mechanisms worked from the organisation's end to them. A small portion of the research questionnaire was given to the workers for which the outcome of the 
feedback is stipulated below.

TABLE 5

COMMUNiCATIVE MECHANISM FEEDBACK By WORKERS

\begin{tabular}{|lc|}
\hline $\begin{array}{l}\text { Questions } \\
\text { 1. All the corrective actions and precautions were taken } \\
\text { when hazards and near misses were identified. }\end{array}$ & Responses in Percentage (\%) \\
\hline $\begin{array}{l}\text { 2. Generally, the physical working milieu is conducive } \\
\text { to suit my needs. }\end{array}$ & 80 \\
\hline $\begin{array}{l}\text { 3. All the safety procedures at my work area was well } \\
\text { observed, even if the work was carried out slowly. }\end{array}$ & 95 \\
\hline $\begin{array}{l}\text { 4. Those workers who were working under my supervision } \\
\text { were consulted well, when resolving workplace issues. }\end{array}$ & 90 \\
\hline $\begin{array}{l}\text { 5. All the safety training information and communication } \\
\text { received assisted me to perform my duties well. }\end{array}$ & 95 \\
\hline $\begin{array}{l}\text { 6. The organisation as a whole demonstrates stronger } \\
\text { commitment towards addressing OHS issues through } \\
\text { effective communication mechanisms. }\end{array}$ & \\
\hline
\end{tabular}

From responses of the feedback received in regards to how communication mechanisms are assisting the workers to curb near misses and injuries at the workplace, it could be stated that the responses were quite appealing and mainly were in the favour of the workers. The identification of corrective actions and precautions to avoid near misses and injures was $90 \%$, while the overall working milieu conducive to the workers stood at $85 \%$. Having a thorough observation of the working area was $95 \%$, with having a clear engagement of workers during resolving workplace issues with their immediate supervisors was $88 \%$. According to the safety and information communication training, $90 \%$ of the workers stated that they received assistance to perform their duties well, while $95 \%$ claimed that the organisation is committed to addressing OHS issues.

\section{CONCLUSION}

The communicative language mechanism tends to provide a supportive and cohesive framework, which allows workers of an organisation and the organisation itself to interact co-operatively and purposefully to minimise workplace injuries. A precise and constructive safety communication system would provide the best mechanism through knowledge and understanding, which can improve and prevent at-risk behaviors by enhancing the safety culture at work. This has been illustrated through the case study that has shown how the organisation responds to decreasing workplace injuries through a repertoire of safety communication mechanisms. So much so, engaging and enhancing effective communication mechanisms is critical to workers since workplace safety is paramount to be addressed by maintaining an optimistic safety culture trend. The organisation needs to be stringent in terms of imparting the effectiveness of communicative language mechanisms concerning occupational health and safety or health and safety environment. It is prudent for the workers of an organisation to strictly adhere to the rules and regulations so that an injury-free working milieu for all the workers is created. In most instances, workers are expected to listen to their line managers for clearer instructions and advice.

More so, the mechanisms need to complement most of the practical and more imperatively the technical safety strategy. Workers with good effective communication skills will be in a better position to be able to provide corrective feedback for all the risky behaviours that are encountered during working hours. Undoubtedly, this will reduce the probability of near misses and other injuries allowing the workers to be extra cautious as much as conscious. In most circumstances, ensuring that workers and organisations adhere to all the protocols of occupational health and safety (OHS) health and safety environment (HSE), it is pivotal to spell all the necessary rules and regulations of occupational health and safety requirements. The study has confirmed that it is not only significant that interaction between workers and organisation is crucial but at the same time, communicative language mechanism also needs to be considered for effective reduction in near misses and injuries. Equally imperative is the fathoming of laws and regulations of occupational health and safety or health and safety environment so that comprehension of these could be seen as a reduction in workplace injuries. Saying that an accident or injury was "bad luck" defines an implication that it cannot be prevented. This is contrary to the expectation and belief that all workplace near misses, accidents and injuries are preventable by identifying risky hazards.

\section{REFERENCES}

[1] Alsamadani, R., Hallowell, M., \& Javernick-Will, A. N. (2013). Measuring and modeling safety communication in small work crews in the US using social network analysis. Construction Management and Economics, 31(6), 568-579.

[2] Amirah, N. A., Asma, W. I., Muda, M. S., \& Amin, W. A. A. W. M. (2013). Safety culture in combating occupational safety and health problems in the Malaysian manufacturing sectors. Asian Social Science, 9(3), 182-186.

[3] Booth, R. (1993). Safety culture: concept, measurement, and training implications. In Proceedings of British Health and Safety. Society Spring Conference: Safety Culture and the Management of Risk, 19-20. 
[4] Buckley, R. (2010). Communications in adventure tour products: Health and safety in rafting and kayaking. Annals of Tourism Research, 37(2), 315-332.

[5] Canale, M. (1983). From communicative competence to communicative language pedagogy. Language and Communication, 1(1), 1-47.

[6] Chen, C. F., \& Chen, S. C. (2013). Upward safety communication and safety behavior of cabin crew. In Proceedings of the Eastern Asia Society for Transportation Studies (Vol. 9, p. 2013).

[7] Clarke, S. (2006). Safety climate in an automobile manufacturing plant. Personnel Review. 10(3), 115-120.

[8] Cole, K. (2000). Crystal Clear Communication: Skills for understanding and being understood. Pearson Education Australia. Pearson Publishers.

[9] Comcare, (2004). Safe and Sound: A discussion paper on safety leadership in government workplaces, Pub 35, August, Canberra, Australia, 125-132.

[10] Conchie, S. M., Moon, S., \& Duncan, M. (2013). Supervisors' engagement in safety leadership: Factors that help and hinder. Safety Science, 51(1), 109-117.

[11] Cook, V. (2013). Second language learning and language teaching. Routledge. 11(4), 156-162.

[12] Donahue, M., Miller, M., Smith, L., Dykes, P., \& Fitzpatrick, J. J. (2011). A leadership initiative to improve communication and enhance safety. American Journal of Medical Quality, 26(3), 206-211.

[13] Geller, E. S. (1998). The psychology of safety: How to improve behaviors and attitudes on the job. Chilton Book Company. USA.

[14] Geller, E. S. (2001). Working safe: How to help people actively care for health and safety. CRC Press. USA.

[15] Geller, E. S. (2002). The challenge of increasing pro-environment behavior. Handbook of Environmental Psychology, 2, 525540.

[16] Geller, E. S. (2005). People-based safety: The source. Coastal Training Technologies. 18(3), 132-142.

[17] Hamid, A. R. A., Abd Majid, M. Z., \& Singh, B. (2008). Causes of accidents at construction sites. Malaysian Journal of Civil Engineering, 20(2), 56-75.

[18] Kapur, R. (2018). Barriers to Effective Communication. Delhi University.

[19] Kaskutas, V., Dale, A. M., Lipscomb, H., \& Evanoff, B. (2013). Fall prevention and safety communication training for foremen: Report of a pilot project designed to improve residential construction safety. Journal of Safety Research, 44, 111-118.

[20] Kim, M. C., Park, J., \& Jung, W. (2008). Sentence completeness analysis for improving team communications of safety-critical system operators. Journal of Loss Prevention in the Process Industries, 21(3), 255-259.

[21] Kines, P., Andersen, L. P., Spangenberg, S., Mikkelsen, K. L., Dyreborg, J., \& Zohar, D. (2010). Improving construction site safety through leader-based verbal safety communication. Journal of safety research, 41(5), 399-406.

[22] Lages, L. F., Jap, S. D., \& Griffith, D. A. (2008). The role of past performance in export ventures: a short-term reactive approach. Journal of International Business Studies, 39(2), 304-325.

[23] Laughery, K. R. (2006). Safety communications: warnings. Applied Ergonomics, 37(4), 467-478.

[24] Lavy, S., Aggarwal, C., \& Porwal, V. (2010). Fatalities of Hispanic workers: Safety initiatives taken by US construction companies to address linguistic and cultural issues. International Journal of Construction Education and Research, 6(4), 271284.

[25] Lesch, M. F. (2005). Remembering to be afraid: applications of theories of memory to the science of safety communication. Theoretical Issues in Ergonomics Science, 6(2), 173-191.

[26] Lijie, C., Tao, T., Xianqiong, Z., \& Schnieder, E. (2012). Verification of the safety communication protocol in train control system using colored Petri net. Reliability Engineering \& System Safety, 100, 8-18.

[27] Littlewood, W., \& William, L. (1981). Communicative language teaching: An introduction. Cambridge University Press. United Kingdom.

[28] Lyneis, J., \& Madnick, S. (2008). Preventing accidents and building a culture of safety: insights from a simulation model. Massachusetts Press. USA.

[29] Maxfield, D., Grenny, J., Lavandero, R., \& Groah, L. (2011). The Silent Treatment. Why Safety Tools and Checklist Aren't Enough to Save Lives. University of Minnesota.

[30] Michael, J. H., Guo, Z. G., Wiedenbeck, J. K., \& Ray, C. D. (2006). Production supervisor impacts on subordinates' safety outcomes: An investigation of leader-member exchange and safety communication. Journal of Safety Research, 37(5), 469-477.

[31] Mullen, J., Kelloway, E. K., \& Teed, M. (2011). Inconsistent style of leadership as a predictor of safety behaviour. Work \& Stress, 25(1), 41-54.

[32] Neal, A., Griffin, M. A., \& Hart, P. M. (2000). The impact of organizational climate on safety climate and individual behavior. Safety Science, 34(1-3), 99-109.

[33] Preece, C., \& Stocking, S. (1999). Safety communications management in construction contracting. In Hughes, W, 15th Annual ARCOM Conference, Liverpool John Moores University.

[34] Qureshi, Z. H. (2008). A review of accident modeling approaches for complex critical sociotechnical systems. Defence Science and Technology Organisation Edinburgh (Australia) Command Control Communications and Intelligence Div.

[35] Reason, J. (2016). Managing the risks of organizational accidents. Routledge. Cambridge University Press.

[36] Rahim, N. A., Ng, H. K., Biggs, D. M., \& Boots, K. (2014). Perception of safety, physical working conditions and stress between Malaysia and United Kingdom. International Journal of Business and Society, 15(2), 321-338.

[37] Reiman, T., \& Rollenhagen, C. (2014). Does the concept of safety culture help or hinder systems thinking in safety? Accident Analysis \& Prevention, 68, 5-15.

[38] Richards, J. C., \& Rodgers, T. S. (2014). Approaches and methods in language teaching. Cambridge University Press. UK.

[39] Rivers, D. (2007). The Seven Challenges: A Guide to Cooperative Communication Skills for Success at Home and at Work. The Modern Language Journal, 70(1), 25-37.

[40] Rivers, W. M. (1986). Comprehension and production in interactive language teaching. The Modern Language Journal, 70(1), 1-7. 
[41] Sherry, M., \& Nancy, Y. (2003). Managing the risk of organizational accidents. Ashgat: Aldershot, UK.

[42] Standards Australia. (2001). Australia/New Zealand Standard AS/NZS 4804 Occupational Health and Safety Management Systems-General guidelines on principles, systems and supporting technique. Sydney, Australia.

[43] Wu, T. C., Liu, C. W., \& Lu, M. C. (2007). Safety climate in university and college laboratories: Impact of organizational and individual factors. Journal of Safety Research, 38(1), 91-102.

[44] Wilkins, J. R. (2011). Construction workers' perceptions of health and safety training programmes. Construction Management and Economics, 29(10), 1017-1026.

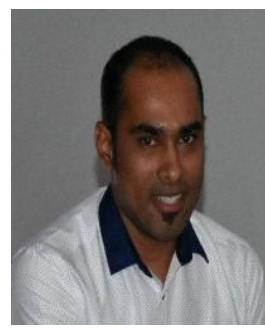

Ravnil Narayan is a Lecturer in Language and Communications in the College of Humanities and Education; School of Communication, Languages and Literature at the Fiji National University's, Ba Campus. As a former high school English language teacher, Narayan's area of interest lies in the field of sociolinguistics, computational linguistics, corpus linguistics, pragmatism, discourse analysis, second language acquisition and $e$-language learning education. He holds a MATESL, PGDTESL, BEd, DSE, DPVL and DHL qualifications. Also, as the former ad hoc translator with AQEP AusAid (Fiji), Narayan is a columnist with The Fiji Times and has published articles in the ranked journals before. Due to the current pandemic, Narayan's Ph.D. in Applied Linguistics is currently on hold from Tsinghua University, Beijing, China. In the interim, he is working towards his next publication for the academic year 2021 titled: The Lexis Praxis of Codeswitching by University Academics in Elucidating Cultural Aspects of Communication in TVET/TEST Classrooms. Narayan hails from the beautiful islands of Fiji in the South Pacific and can be contacted on ravnil.narayan@fnu.ac.fj or ravnilnarayan@gmail.com

(Ravnil is the Principal Corresponding Author of this article)

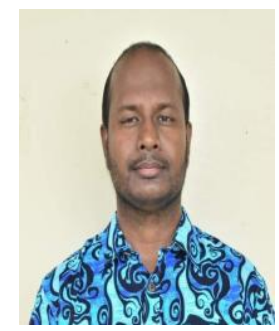

Vikrant Krishan Nair is an Assistant Lecturer in Occupational Health and Safety under the School of Applied Sciences at the Fiji National University and is based in Ba campus. He has worked at various organisations in the private sector before joining the world of Academia and with the zeal to update his knowledge, he has been upgrading his qualifications on the latest practices and trends in Human Resource areas concerning Labour laws, Management, Technology, and Occupational Health \& Safety. He holds an MBA, PGDEM, PGDBA, PGCBA, PDBL, Dip. OHS, Cert IV. OHS, TC in Fitting \& Machining and various other OHS training qualifications. Nair has done a few local publications, including being a columnist with the Fiji Times and is currently working towards his second Masters degree, which is in Entrepreneurship and Management together with his next publication for the academic year 2021. Nair is a Fijian citizen and can be contacted via email Vikrant.Nair@fnu.ac.fj or criznan@gmail.com 